\title{
Flavor profiles of monovarietal virgin olive oils produced in the Oriental region of Morocco
}

\author{
Farid Mansouri ${ }^{1, *}$, Abdessamad Ben Moumen ${ }^{1}$, Gaetan Richard $^{2}$, Marie-Laure Fauconnier ${ }^{2}$, \\ Marianne Sindic ${ }^{3}$, Hana Serghini Caid ${ }^{1}$ and Ahmed Elamrani ${ }^{1}$ \\ ${ }^{1}$ Laboratory of Plants \& Microorganisms Biology, Faculté des Sciences Oujda - Université Mohammed Premier, BP-717, \\ 60000 Oujda, Morocco \\ ${ }^{2}$ General and Organic Chemistry Unit, Gembloux Agro-BioTech - Université de Liège, Passage des Deportes 2 , \\ 5030 Gembloux, Belgium \\ ${ }^{3}$ Laboratory Food Quality and Safety, Analysis Quality and Risk Unit, Gembloux Agro-BioTech - Université de Liège, \\ Passage des Deportes 2, 5030 Gembloux, Belgium
}

Received 20 October 2016 - Accepted 7 March 2017

\begin{abstract}
The purpose of this study is the evaluation of flavor profiles of monovarietal virgin olive oils (VOO) produced in the Oriental region of Morocco via the characterization of volatile compounds, using SPME-GC/MS technique, and the determination of total phenolic content (colorimetric method). The study concerns oils of three European olive cultivars (Arbosana, Arbequina and Koroneiki) which were recently introduced in Morocco under irrigated high-density plantation system. GC/MS aroma profiles of analyzed VOOs showed the presence of 35 volatile compounds. The major compounds in such oils are C6 compounds produced from linoleic and linolenic acids via lipoxygenase pathway such as trans-2-hexenal, cis-2-hexenal, cis-3-hexen-1-ol, trans-3-hexen-1-ol, trans-3-hexen-1-ol acetate, hexanal and 1-hexanol in different proportions depending on the cultivar $(p<0.05)$. In addition, statistical analyses indicate that the analyzed VOOs have different aroma profiles. Arbequina oil has a high proportion of compounds with sensory notes "green" and "sweet" giving it a fruity sensation compared to Arbosana and Koroneiki. In parallel, Arbosana and Koroneiki oils are rich in phenolic compounds and provide relatively bitter and pungent tastes to these oils.
\end{abstract}

Keywords: virgin olive oil / volatile compounds / phenols / solid phase micro extraction

Résumé - Profils organoleptiques d'huiles d'olive vierges monovariétales produites dans la région orientale du Maroc. Le but de cette étude vise l'évaluation des profils organoleptiques des huiles d'olive vierges monovariétales produites dans la région orientale du Maroc par la caractérisation des composés volatils et la détermination de la teneur en phénols totaux. Il s'agit d'huiles d'olive de trois cultivars d'origine européenne (Arbequina, Arbosana et Koroneiki) récemment introduites au Maroc en irriguée super-intensif. Les profils aromatiques obtenus par GC/MS des huiles analysées montrent la présence de 35 composés volatils. Les principaux composés présents dans ces huiles sont les composés C6, tels que le trans-2-hexénal, le cis-2-hexènal, le cis-3-hexén-1-ol, le trans-3-hexén-1-ol, l'acétate de trans-3-hexén-1ol, le 1-héxanol et l'hexanal à des proportions différentes selon le cultivar $(p<0,05)$. En outre, les analyses statistiques indiquent que les huiles analysées ont des profils aromatiques différents. L'huile d'Arbéquina présente une forte proportion des composés offrant des notes sensorielles «vert» et «sucré» lui conférant une sensation de fruité par rapport à l'Arbosana et Koroneiki. En parallèle, les huiles Arbosana et Koroneiki sont riches en composés phénoliques et apportent des goûts relativement amer et piquant à ces huiles.

Mots clés : huile d'olive vierge / composes volatils / phenols / micro extraction en phase solide

\footnotetext{
${ }^{*}$ Correspondence: f.mansouri@ump.ac.ma
} 


\section{Introduction}

Virgin olive oil (VOO) is the ultimate Mediterranean product. It is increasingly becoming a part of the eating habits of new consumers worldwide nowadays. Its global consumption increased significantly during the past 25 years, from 1985000 to 3075500 tonnes (IOOC, 2015c). This increase is mainly associated to the unique characteristics of VOOs such as: nutritional properties, aroma, taste and color (Gutiérrez et al., 1999).

In Morocco, olive has been thus far a traditional culture, yet it occupies a privileged place in agriculture contributing $5 \%$ of Gross Domestic Product (MAPM, 2014). The olive sector is a future opportunity in the increase in demand coupled with Moroccan agricultural policy through Green Morocco plan. It plans to expand from 760000 to 1220000 ha for the period of 2008-2020 (MAPM, 2014), adopting a super-intensive system. This allows the intensification of production with densities ranging from 1200 to 2500 trees/h (Benito et al., 2013).

Among the suitable olive varieties for intensive cultivation, three have been recently adopted in Morocco; Spanish cultivars Arbequina and Arbosana, and Greek cultivar Koroneiki. They are intended for the production of olive oil (Godini et al., 2011). The choice of these varieties by growers is due to several reasons, mainly their erected habit and low vigor, their precocity and their oil richness in comparison with autochthone varieties as well as their excellent quality (Allalout et al., 2009; Russo et al., 2014; Mansouri et al., 2016).

The high quality of VOO is determined largely by its organoleptic characteristics. These fine properties are particularly related to the presence of phenolic and volatile compounds (Angerosa, 2002; Andrewes et al., 2003; Cerretani et al., 2008). The former compounds are responsible for giving olive oil the following sensory properties: pungency and bitterness (Andrewes et al., 2003; Beltran et al., 2007) while the latter compounds are responsible for sensory notes green and fruity (Angerosa, 2002; Cerretani et al., 2008).

The volatile compounds are low molecular weight molecules which are volatile at room temperature (Angerosa, 2002). They are products of oxidation of unsaturated fatty acids (Kalua et al., 2007). In fact, the products of oxidation by lipoxygenase (endogenous enzymes of olive tree) are responsible for the positive perceptions of VOO flavors, while substances of auto-oxidation and photo-oxidation are generally associated to sensory defects (Kalua et al., 2007).

The majority of molecules produced via lipoxygenase pathway are C5 and C6 compounds produced during oil manufacturing process and during its storage (Kalua et al., 2007). The action of lipoxygenase on linolenic acid and linoleic acid causes the formation of 13-hydroperoxydes, the substrates for the rest of enzymatic reactions leading to the formation of volatile compounds (Angerosa et al., 1999; Luaces et al., 2007).

The level and activity of enzymes involved in different pathways of the lipoxygenase influence the composition of the olive oil volatile fraction (Angerosa, 2002). These enzymes are genetically determined and influenced in particular by the stage of maturity of olives (Campeol et al., 2001; Kandylis et al., 2011), cultivation methods (García-González et al., 2014), extraction methods and storage conditions (Vekiari et al., 2007; Servili, 2014) and geographical origin (Temime et al., 2006; Bajoub et al., 2015).

Studies on the composition and quality of monovarietal VOO from Arbequina, Arbosana and Koroneiki recently introduced in the Oriental region of Morocco have been conducted. They have focused on major and minor compounds (Mansouri et al., 2016). However, little is known about the quality of these oils especially sensory quality. Hence why this study aims to determine the flavor profiles of these three monovarietal VOOs by the characterization of volatile compounds and the assessment of the total phenolic content.

\section{Materials and methods}

\subsection{Samples}

The analyzed oil samples are from three olive varieties recently introduced in the Oriental region of Morocco: Arbequina, Arbosana and Koroneiki. These three cultivars are planted since 2007 in a private estate located in the plain of Angad (latitude: $34^{\circ} 47^{\prime} \mathrm{N}$, longitude: $001^{\circ} 57^{\prime} \mathrm{W}$, altitude: $458 \mathrm{~m}$ ) north-east of Morocco. These are irrigated superintensive varieties planted with a density of 1666 trees/ha with a distance of $1.5 \mathrm{~m} / 4 \mathrm{~m}$ between the trees. The irrigation period is 10 months a year, from January to October.

This study examined three samples of each variety, each sample contains 30 trees. The olives were harvested at the last week of November of the 2013/2014 harvesting season with a ripening index of 3.8-4.0. The olive ripening index was determined according to the method developed by the Agronomic Station of Jaén (Uceda and Hermoso, 1998). This maturity stage is the stage of the change in color from yellowgreen olives to purple ones (rotating color).

The harvested olives by straddle harvesters are triturated immediately by a two-phase centrifugation system "Pieralisi" in the "Huiles d'olive de la Méditerranée-Oujda, Maroc" company factory. After deleafing and washing, the olives are crushed by a hammer mill. The obtained olive paste was mixed at $27^{\circ} \mathrm{C}$ for $30 \mathrm{~min}$ and then centrifuged using a horizontal two-phase centrifuge without addition of water. Thereafter, the oil passes into a vertical centrifuge to remove the maximum of water.

Although physicochemical quality analysis (acidity, peroxide value and UV absorbance) is carried out on site at the factory, all the physicochemical quality tests were retaken in the laboratory using the methods described in the European Commission standard (EEC, 2003). All analyzed oils have values that meet the standards set by the International Olive Oil Council (IOOC, 2015b) for the category of extra virgin olive oils (moisture $\leq 0.1 \%$; acidity $\leq 0.8 \%$, peroxide value $\leq 20 \mathrm{meq} \mathrm{O}_{2} \mathrm{~kg}^{-1} ; K_{270} \leq 0.22 ; K_{232} \leq 2.5$ and delta $\left.K \leq 0.01\right)$.

\subsection{Determination of total phenols}

The extraction of phenolic compounds was performed according to the method described by Ollivier et al. (2004) using a methanol/water mixture $(80 / 20 ; \mathrm{v} / \mathrm{v})$. The total phenol content was determined by the Folin-Ciocalteu method (Folin 
and Ciocalteu, 1927) described by Ollivier et al. (2004) using caffeic acid (Sigma-Aldrich, St. Louis, MO, USA) as standard. The results are expressed in milligrams caffeic acid per kilogram olive oil.

\subsection{Analysis of volatile compounds}

Analysis of the oil's volatile fraction was performed using the solid phase micro extraction (SPME) technique and gas chromatography (GC-7890A, Agilent Technologies, Palo Alto, CA, USA) equipped with an automatic injector and coupled with quadrupole-type mass spectroscopy (MS-5975C, Agilent Technologies, Palo Alto, CA, USA). For this, $2.5 \mathrm{~g}$ of oil were placed in a $20 \mathrm{ml}$ vial and preincubated at $40{ }^{\circ} \mathrm{C}$ for $10 \mathrm{~min}$. Volatile compounds in the vials' headspace were adsorbed on a SPME fiber $(50 / 30 \mu \mathrm{m}$ DVB/Carboxen/ PDMS; Supelco, Bellefonte, PA, USA) for $50 \mathrm{~min}$. After the extraction, the volatile compounds were desorbed directly in the injector of the device.

The separation of volatile compounds was done in splitless mode on a DB-Wax ms capillary column $(30 \mathrm{~m} \times 0.25 \mathrm{~mm}$, $0.25 \mu \mathrm{m}$ film thickness; Agilent Technologies, PaloAlto, CA, USA). The used carrier gas is helium $(99.999 \%$, Air Liquide, Liège, Belgium) at a flow rate of $1.5 \mathrm{ml} / \mathrm{min}$. The initial oven temperature was $40^{\circ} \mathrm{C}$, kept for $6 \mathrm{~min}$, then the temperature was raised at a rate of $6^{\circ} \mathrm{C} / \mathrm{min}$ up to $128^{\circ} \mathrm{C}$ followed by an increase of $20^{\circ} \mathrm{C} / \mathrm{min}$ up to $250^{\circ} \mathrm{C}$ and then this temperature was maintained for $10 \mathrm{~min}$.

Mass spectra were performed using a method of ionization by electron impact of $70 \mathrm{eV}$ (source temperature: $230^{\circ} \mathrm{C}$ and quadrupole temperature: $150{ }^{\circ} \mathrm{C}$ ) and recorded at a speed of $4.27 \mathrm{scans} / \mathrm{s}$ for a range of 35-400 amu (atomic mass unit).

Volatile compounds were identified by comparing their mass spectra with those of PAL600K (Palisade Corporation, USA) and Wiley 275 Spectral databases. The identification of volatile compounds was also carried out by calculating their Kovats retention indices (KI). KI were determined by injecting a hydrocarbon mixture containing a series of alkanes (C7-C30; $1000 \mu \mathrm{g} / \mathrm{ml}$ in hexane, Supelco, Bellefonte, PA, USA) under the same conditions described above.

\subsection{Statistical analyses}

The results presented in this work are the means of analyses carried out in triplicate with corresponding standard deviations $( \pm \mathrm{SD})$. The normality of these results was evaluated by the test of the right Henry. The one-way ANOVA statistical analysis and the Duncan Post-hoc test were used to determine the significant differences between the means. The significant difference threshold was set at 5\%. The Principal Components Analysis (PCA) was performed on the data sets in order to determine the variables that differentiate the flavor properties of VOOs analyzed depending on the cultivar. The similarities between the analyzed varieties are determined by the hierarchical clustering test.

The applications of these statistical analyses were performed using Windows softwares: IBM Statistical Package for the Social Sciences (SPSS 20.0) and XLSTAT, Version 5.16.03 (Addinsoft, 2014).

\section{Results and discussion}

The sensory evaluation of VOOs is designed to measure the intensity of olfactory and gustatory sensations of perceived flavors. These sensations are primarily modulated by the presence of volatile and phenolic compounds (Cerretani et al., 2008). The latter compounds are considered the main antioxidants in olive oil and contribute to the oxidative stability of the oil (Botia et al., 2001; Allalout et al., 2009). Moreover, these compounds are responsible for some key sensory properties of olive oil (Andrewes et al., 2003; Beltran et al., 2007). The results of the determination of total phenols, by the colorimetric method, of the analyzed VOOs show levels that fluctuate between 286 and $567 \mathrm{mg}$ of caffeic acid per kg of olive oil. This is well in line with the values suggested by the work of Aguilera et al. (2005), who reported that the total phenol concentration in VOO can vary between 50 and $1000 \mathrm{mg} \mathrm{kg}^{-1}$, depending on various factors such as cultivar, climate, location, degree maturation and the production process of olive oil. According to Figure 1, total phenols content is clearly influenced by the cultivar $(p<0.05)$. VOO from Koroneiki variety is the richest in total phenols with a content of $566.30 \mathrm{mg} \mathrm{kg}^{-1}$, while the lowest concentration was recorded in Arbequina oil whose content of phenols is $286.51 \mathrm{mg} \mathrm{kg}^{-1}$. Arbosana oil has an intermediate concentration of phenols $\left(454.80 \mathrm{mg} \mathrm{kg}^{-1}\right)$. Based on these results and according to the sensory classification of VOOs based on phenolic content published by Beltran et al. (2007), we can deduce that the Arbosana and Koroneiki VOOs can be classified respectively in the bitter quite/very bitter and bitter oil categories, while the Arbequina oil can be classified in the light bitterness category. The bitterness and pungency perceptions are due to complex phenolic compounds. In fact, an oil containing many complex phenols such as secoiridoid derivatives will be more bitter and pungent (Andrewes et al., 2003; Barbieri et al., 2015). The majority of pungent sensations in VOO was attributed to decarboxymethyl ligustroside aglycone (Andrewes et al., 2003; Barbieri et al., 2015), meanwhile, decarboxymethyl oleuropein aglycone is regarded as the main cause of bitterness (Barbieri et al., 2015). In our previous study (Mansouri et al., 2016), we demonstrated that decarboxymethyl oleuropein aglycone and decarboxymethyl ligustroside aglycone constitute the fraction of secoiridoid derivatives and constitute the majority of the identified phenolic compounds in the analyzed VOOs (over $90 \%$ ) and their contents vary in the same order as total phenols. Thus, this demonstrates respective tastes of the oils of our analyzed varieties.

Beyond the contribution of phenolic compounds to the sensory determination of VOO, flavor is an important component and criterion to distinguish between VOOs of different olive varieties. This unique and delicate flavor of $\mathrm{VOO}$ is attributed to the presence of volatile compounds. Table 1 summarizes the proportions of volatile compounds of analyzed VOOs which are determined by integrating the areas under the peaks of the chromatograms obtained by SPME-GC/ MS technique. A total of 35 compounds were identified for VOO of Arbosana variety, 34 for Arbequina and 33 for Koroneiki. The identified volatile compounds are mainly aldehydes (14.28-57.67\%), alcohols (23.49-29.30\%), esters 


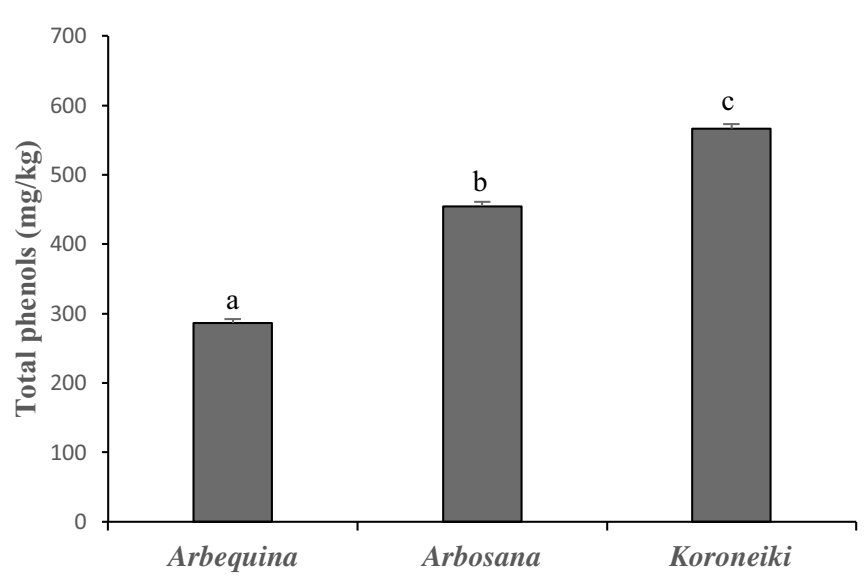

Fig. 1. Total phenols content of the studied virgin olive oils produced in Oriental region of Morocco. Significant differences $(p<0.05)$ are indicated by different letters $(\mathrm{a}-\mathrm{c})$. Concentration of total phenols expressed as milligram of caffeic acid per kilogram of olive oil (colorimetric method).

(5.05-31.51\%) and carboxylic acids (4.53-15.47\%). These four chemical classes represent more than $90 \%$ of identified compounds in the analyzed samples. Aldehydes constitute the major fraction in Arbosana and Arbequina oils with, respectively, 55.87 and $57.67 \%$. While esters and alcohols account for the majority of fractions in Koroneiki oil (29.30 and $31.51 \%$, respectively).

The main substances that constitute volatile compounds of studied VOOs are molecules with 6 (C6) and 5 (C5) carbon atoms mainly aldehydes, esters and alcohols. These substances are produced from polyunsaturated fatty acids via lipoxygenase pathway (Cavalli et al., 2004). The level of these compounds depends on the concentration and the activity of each enzyme involved in this pathway, and the fatty acid composition of the oil, which are also dependent on olive variety (Garcia et al., 2012). This may explain the significant differences $(p<0.05)$ observed between these compounds on the analyzed VOOs. The total proportion of these molecules represents $61.18 \%$ of the volatile compounds in Koroneiki oil, $86.12 \%$ in Arbequina and $87.27 \%$ in Arbosana variety. The dominance of these compounds results in a good quality of these oils, because the $\mathrm{C} 5$ and $\mathrm{C} 6$ molecules represent the largest fraction of volatile compounds in VOOs of high quality in quantitative terms (Reboredo-Rodríguez et al., 2014). In fact, the C6 compounds represent more than $70 \%$ of the volatile fraction in Arbequina and Arbosana oils, while the lowest portion is recorded in Koroneiki oil (48.82\%). In addition, this fraction is dominated by the compounds from the degradation of linolenic acid by lipoxygenase (more than $85 \%$ of C6) such as trans-2-hexenal, cis-2-hexenal, trans, trans-2,4-hexadienal, trans-3-hexen-1-ol, cis-3-hexen-1-ol, cis-3-hexen-1-ol acetate and trans-2-hexen-1-ol (Fig. 3).

The main esters in the analyzed VOOs are methyl acetate, ethyl acetate, acetate cis-3-hexen-1-ol and hexyl acetate. The latter contributes to the sensory rating of "sweet" and "fruity" (Kalua et al., 2007), while acetate cis-3-hexen-1-ol is related to pleasant notes "green" and "banana" (Baccouri et al., 2008). Methyl acetate and ethyl acetate also contribute to the "green"

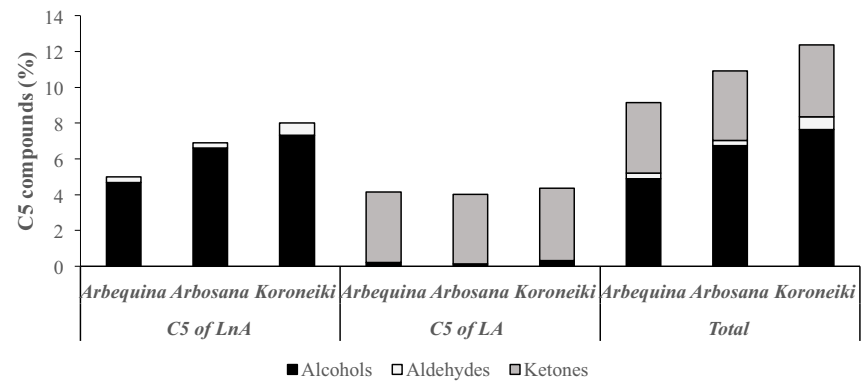

Fig. 2. Percentages of C5 volatile compounds derived from lipoxygenase of linoleic (LA) and linolenic (LnA) acids in monovarietal virgin olive oils of Morocco's Oriental region. C5 of LA: 1-pentanol and 3-pentanone; C5 of LnA: 1-penten-3-ol, trans-2pentenal and cis-2-penten-1-ol.

and "sweet" notes, respectively (García-González and Aparicio, 2010). However, other authors suggest that ethyl acetate contributes negatively to the flavor of olive oil by adding a winey-vinegary flavor (Morales et al., 2005; IOOC, 2015a). VOO from Koroneiki variety has the highest proportion of esters $(31.51 \%)$ compared to Arbosana $(8.83 \%)$ and Arbequina (5.05\%). The low levels of hexyl acetate and cis-3-hexen-1-ol acetate in Arbequina and Arbosana oils may be due to low activity of the alcohol acyl transferase which is involved in the generation of C6 esters (Ridolfi et al., 2002).

The alcoholic fraction is composed mainly by $\mathrm{C} 5$ and $\mathrm{C} 6$, such as 1-penten-3-ol, 1-pentanol, cis-2-penten-1-ol, 1hexanol, trans-3-hexen-1-ol, cis-3-hexen-1-ol and trans-2hexen-1-ol (Figs. 2 and 3). In all analyzed VOOs, the proportions of $\mathrm{C} 6$ are superior to those of $\mathrm{C} 5$ compounds. Koroneiki oil is characterized by high levels of C6 and C5 alcohols (19.46 and $7.65 \%$, respectively) compared to Arbequina (17.37 and 4.89\%, respectively) and Arbosana (15.03 and $6.74 \%$ respectively). cis-3-Hexen-1-ol is the major component of this fraction with a proportion ranging from 8.80 (Arbosana oil) and $14.53 \%$ (Koroneiki oil) followed by trans2-hexen-1-ol (2.14-3.74\%) and 1-hexanol (2.30-4.46\%). The presence of trans-3-hexen-1-ol and trans-2-hexen-1-ol in VOO also contribute to sensory note "green", while 1-hexanol gives the oil a "fruity" sensation (Kalua et al., 2007). The rest of the alcoholic fraction molecules are present in all samples, but at low levels. Their presence in the oil could have a positive impact on the sensory level generally contributing to the sensory note "fruity" and "green" (Kalua et al., 2007). In addition, high levels of alcohol compounds in Koroneiki oil are probably related to an intense enzymatic activity of alcohol dehydrogenase, which results in the reduction of aldehydes to alcohols (Brkić Bubola et al., 2012). On the other hand, Angerosa et al. (1999) suggest that the activity of this enzyme is genetically determined for each cultivar.

Table 1 shows also a significant difference $(p<0.05)$ in the proportions of identified aldehyde compounds. This fraction is constituted exclusively by $\mathrm{C} 5$ and $\mathrm{C} 6$ compounds, in various proportions depending on the cultivar. Arbequina and Arbosana oils are characterized by higher proportions of aldehyde compounds (57.67 and $55.87 \%$, respectively) than those observed in Koroneiki oil (14.28\%). trans-2-Hexenal, 
Table 1. Percentage peak areas of identified volatile compounds by SPME-GC/MS technique in monovarietal virgin olive oils of Morocco's Oriental region.

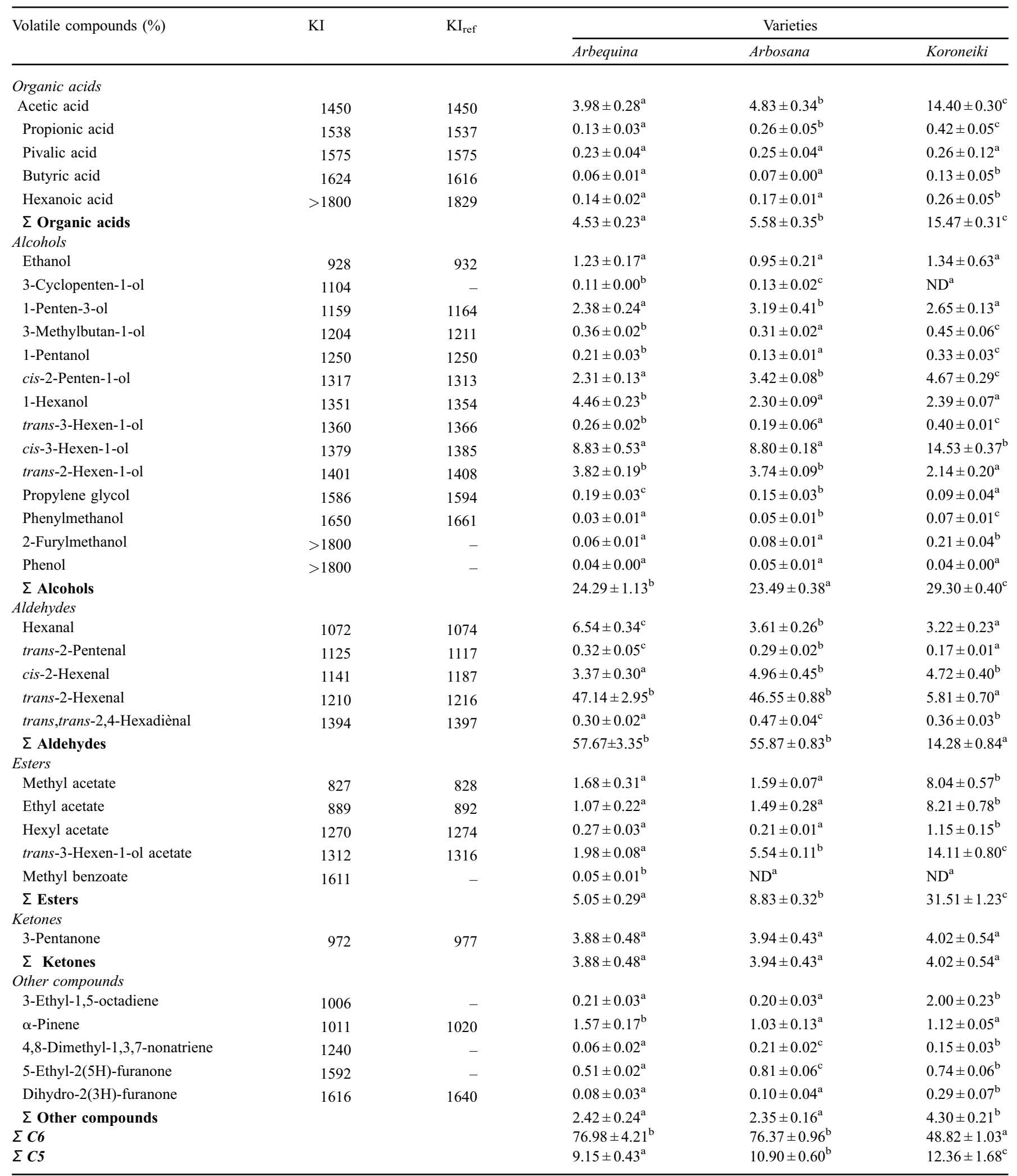

The values are the means of three different olive oil samples \pm standard deviation. Significant differences $(p<0.05)$ in the same line are indicated by different letters $(\mathrm{a}-\mathrm{c})$. KI, Kovats Index calculated on DB-Wax column; $\mathrm{KI}_{\text {ref }}$, literature Kovats index using DB-Wax stationary phase (Wong and Bernhard, 1988; Buttery et al., 2000; Ruther, 2000; Ferreira et al., 2001; Umano et al., 2002; García-González et al., 2007; García-González and Aparicio, 2010); ND, not identified. 


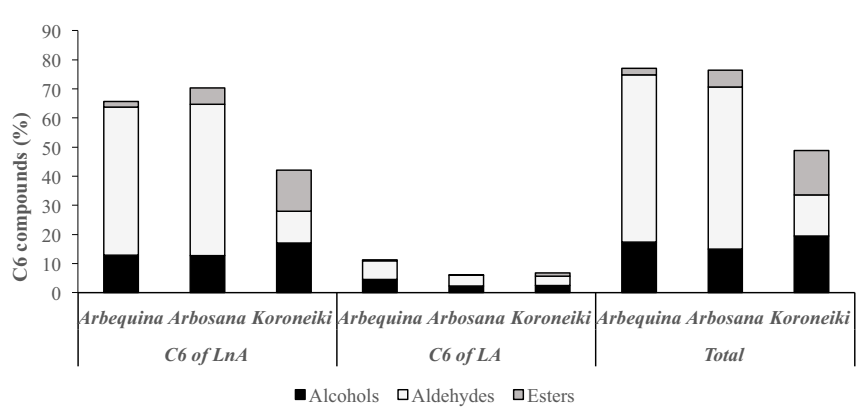

Fig. 3. Percentages of $\mathrm{C} 6$ volatile compounds derived from lipoxygenase of linoleic (LA) and linolenic (LnA) acids in monovarietal virgin olive oils of Morocco's Oriental region. C6 of LA: hexyl acetate, 1-hexanol and hexanal; C6 of LnA: cis-2-hexenal, trans-2-hexenal, trans,trans-2,4-hexadienal, cis-3-hexen-1-ol acetate, cis-3-hexen-1-ol, trans-3-hexen-1-ol and trans-2-hexen-1-ol.

which develops "green" aroma or "fresh cut grass" (Kalua et al., 2007), is among the main volatile compounds identified in Arbequina and Arbosana oils (47.14\% and 46.55\%, respectively) while it is present in a very low proportion in Koroneiki oil (5.81\%). This large difference between analyzed VOOs may be due to the intense activity of isomerization enzymes in the Arbequina and Arbosana varieties. According to Cavalli et al. (2004), trans-2-hexenal can be formed from 13-hydroperoxyde via cis-3-hexenal, which is either rapidly isomerized into trans-2-hexenal by two isomerases or reduced into cis-3-hexenol by dehydrogenase. In addition, trans-2hexenal has been used by some authors as a marker of freshness of VOOs (Cavalli et al., 2004).

The remaining aldehyde fraction of the studied oils comprises hexanal, trans,trans-2,4-hexadienal, trans-2-pentanal and cis-2-hexenal. Hexanal is considerably present in all tested oils. Arbequina oil has the highest rate $(6.54 \%)$ compared to that of Arbosana (3.61\%) and Koroneiki (3.22\%). The high levels of hexanal, are often linked to sensory notes "sweet", "apple" and "green" (Kalua et al., 2007).

3-pentanone was also detected with significant proportions in all samples. It is the result to the detriment of C6 alcohols and aldehydes formation via homolysis of 13-hydroperoxide (Cavalli et al., 2004). Its presence in oil brings a spicy sensation. Koroneiki $\mathrm{VOO}$ has the highest rate in 3-pentanone (4.02\%), while Arbequina and Arbosana VOOs have low and similar proportions (3.88 and 3.94\% respectively).

Carboxylic acids such as acetic acid, propionic acid, pivalic acid, butyric acid and hexanoic acid were also identified in analyzed oils. Acetic acid is the major component of this fraction with proportions of 3.98\% (Arbequina oil) and $10.38 \%$ (Koroneiki oil). The presence of this compound in olive oil may be due to a process of fermentation in the olives which is responsible for the vinegary sensory defect in VOO (Kalua et al., 2007).

Moreover, the results for VOOs from Spanish olive varieties cultivated in Morocco are in agreement with the previous results reported in other studies (Reboredo-Rodríguez et al., 2013a, b; Angerosa et al., 2004), where trans-2-hexenal is the main compound of the volatile fraction of the olive oils produced in Spain.
On the other hand, olive oil from the Koroneiki variety cultivated in Morocco presents a different profile compared to the results reported in Greece (Kandylis et al., 2011; Kosma et al., 2015). In fact, our results showed that the olive oil from Koroneiki variety has a low proportion of trans-2-hexenal. This could be explained by the influence of environmental factors (Temime et al., 2006; Kandylis et al., 2011; Bajoub et al., 2015), albeit they are unacknowledged by other studies (Angerosa et al., 2004; Zhu et al., 2013; Zhu et al., 2015). These sources suggest that trans-2-hexenal concentration and C6 proportions are not affected by origin and climate; these two parameters would be differentiation markers of monovarietal VOOs.

The identification of changes in volatile compounds of oils of the studied varieties led us to perform a PCA on the identified compounds to study the structure of data and to characterize the oil samples based on their compositions in the headspace of the oils and their total phenols content. The results of the PCA have enabled us to isolate twenty-three factors explaining $100 \%$ of the analyzed variances, the first two accounted $79.78 \%$ of the total information. The most contributing of factor 1 are methyl, ethyl and hexyl acetates and $\mathrm{C} 6$ compounds produced from the lipoxygenase pathway such as cis-3-hexen-1-ol, hexyl acetate, trans-2-hexenal and trans-2-hexen-1-ol (Tab. 2). These compounds are responsible for positive sensory notes such as "green" (Kalua et al., 2007). Organic acids, mainly acetic acid, are part of the variables that present a strong correlation with factor 1 . They are often responsible for sensory defects linked to vinegary and pungency (Kalua et al., 2007). Other compounds showed a strong correlation with factor1 such as 3-ethyl-1,5-octadiene. The attribution of a sensory note to this compound in the definition of VOO flavor is not clear. In fact, few studies reported the presence of these compounds in VOO without taking their sensory role into consideration (Vichi et al., 2003; Tanouti et al., 2012). Overall, the volatile compounds with higher levels in Koroneiki VOO have mainly a positive correlation with factor 1. On the other hand, 1-hexanol, trans, trans-2,4-hexadienal, methyl benzoate, hexanal have the most significant correlation with factor 2. Figure 4 shows a projection of different cultivars in the factorial plane defined by the first two main components. The representation of the first factors allows a clear separation for the analyzed samples. Koroneiki is completely opposite of Arbequina and Arbosana on the first factor axis. This means that Koroneiki is very different from the Spanish varieties, since the first axis is the one that separates the points best because it explains $61.48 \%$ of the information.

The results obtained by PCA were confirmed by the hierarchical cluster test. In fact, the dendrogram obtained from this analysis shows that at a distance of 59.97 cultivars are divided into three groups (Fig. 5). Cluster 1 is formed by the cultivar Arbequina, distinguished from other varieties by a high proportion of C6 compounds and low mean value of total phenols. Koroneiki variety that forms cluster 3 , is characterized by high mean values of cis-3-hexen-1-ol, esters, organic acids and total phenols. While cluster 2 includes Arbosana which has intermediate values of these parameters. In addition, at a distance of 282.65 , oils of the studied varieties are divided into two major groups. The first consists of Arbequina and Arbosana which are characterized by high levels of $6 \mathrm{C}$ 
Table 2. Factor loading of parameters classified according to the cultivar on PCA plot.

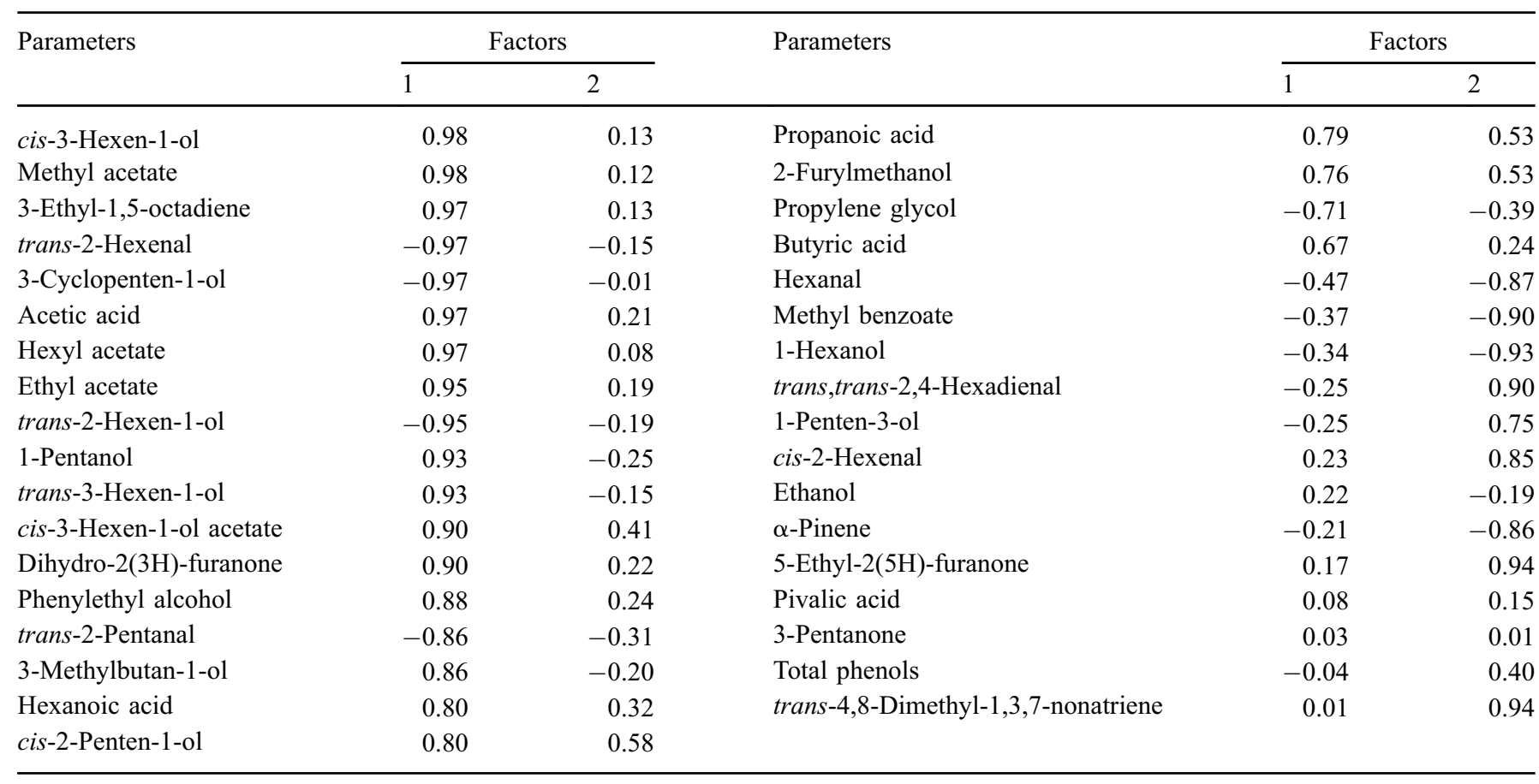

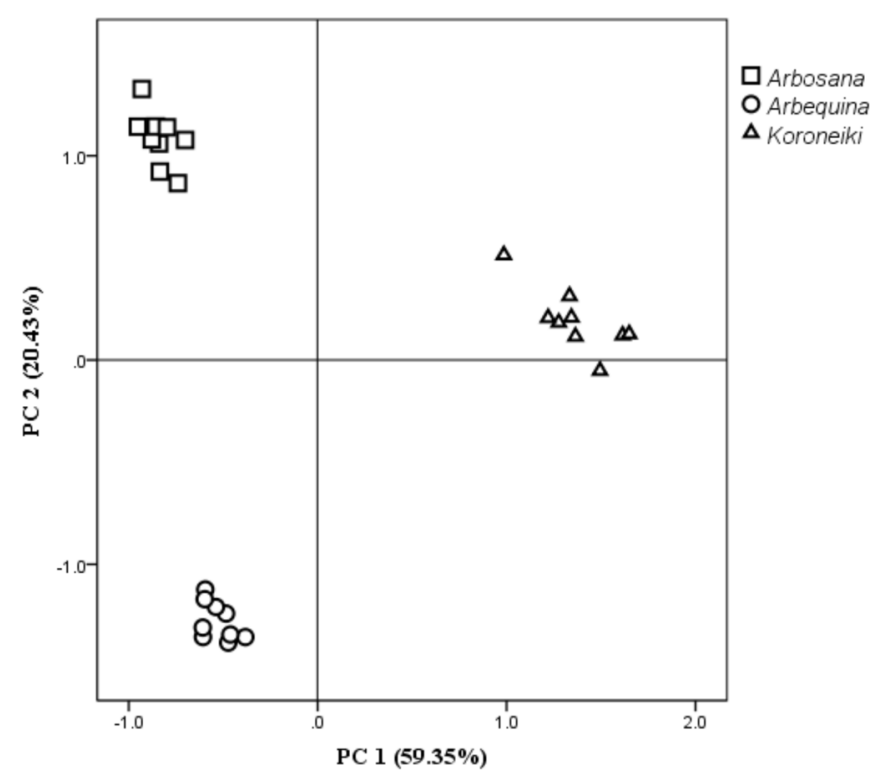

Fig. 4. PCA plot with factors 1 and 2 based on 36 variables (volatile compounds and total phenols) of the studied virgin olive oils.

compounds. Both varieties are also characterized by small percentages of esters and organic acids compared with those of Koroneiki oil which forms the second group.

\section{Conclusion}

Analysis of the volatile fraction of oil samples of European varieties produced in the Oriental region of Morocco by SPME-GC/MS has enabled us to identify the presence of 35

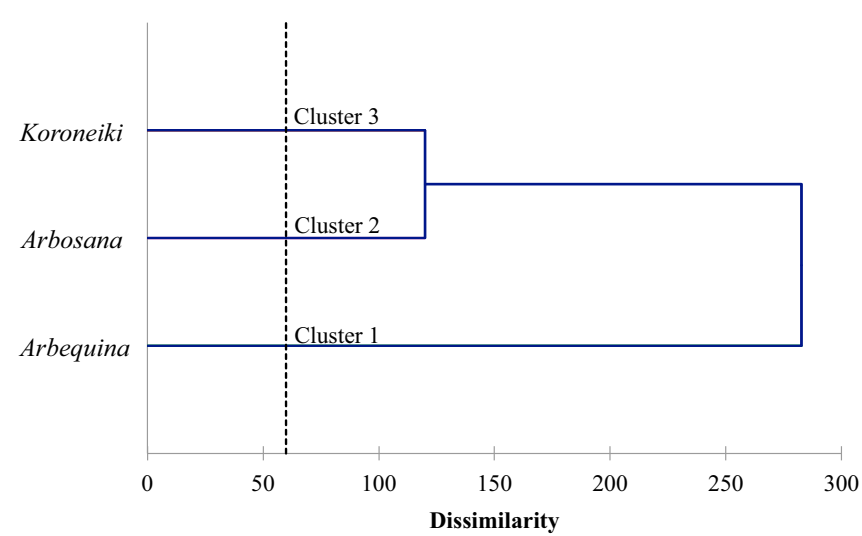

Fig. 5. Euclidean distance dendrogram of volatile compounds and total phenols of monovarietal virgin olive oils of Morocco's Oriental region.

compounds from different chemical classes (mainly aldehydes, alcohols, esters and carboxylic acids). The proportions of the majority of the identified compounds clearly vary depending on the cultivar $(p<0.05)$. The major volatile compounds in these oils are C6 compounds, such as trans-2hexenal, hexanal acetate, cis-3-hexen-1-ol, trans-2-hexen-1-ol and 1-hexanol. In addition, statistical analyses of hierarchical cluster and principal components showed that the three analyzed VOOs have different flavor profiles. Compared to Arbosana and Koroneiki, Arbequina variety oil showed a high proportion of compounds which are responsible for sensory notes "green" and "sweet" giving it a fruity sensation. As for Arbosana and Koroneiki oils, their richness in phenolic compounds makes them taste bitter. 
The low phenolic content of the Arbequina oil is the cause of its instability to oxidation and therefore its low storability. Preservation of the best sensory quality of Arbequina oil could be achieved by a meticulous assembling with oils of the other two varieties. This would at the same time help create new products, diversifying the consumer choice.

Acknowledgements. We are grateful to the "MoroccanBelgian cooperation program" for the financial support of this research through a "WBI-Projet 2/9, 2012-2014". Our thanks are also due to the Company "Huiles d'olive de la Méditerranée" for its collaboration and Mr. Abdelouadoud Omari for the time spent in reviewing this paper.

\section{References}

Aguilera MP, Beltrán G, Ortega D, Fernández A, Jiménez A, Uceda M. 2005. Characterisation of virgin olive oil of Italian olive cultivars: 'Frantoio' and 'Leccino', grown in Andalusia. Food Chem 89: 387-391.

Allalout A, Krichène D, Methenni K, et al. 2009. Characterization of virgin olive oil from super intensive Spanish and Greek varieties grown in northern Tunisia. Sci Hortic 120: 77-83.

Andrewes P, Busch JL, de Joode T, Groenewegen A, Alexandre H. 2003. Sensory properties of virgin olive oil polyphenols: identification of deacetoxy-ligstroside aglycon as a key contributor to pungency. J Agric Food Chem 51: 1415-1420.

Angerosa F. 2002. Influence of volatile compounds on virgin olive oil quality evaluated by analytical approaches and sensor panels. Eur J Lipid Sci Technol 104: 639-660.

Angerosa F, Basti C, Vito R. 1999. Virgin olive oil volatile compounds from lipoxygenase pathway and characterization of some Italian cultivars. J Agric Food Chem 47: 836-839.

Angerosa F, Servili M, Selvaggini R, Taticchi A, Esposto S, Montedoro G. 2004. Volatile compounds in virgin olive oil: occurrence and their relationship with the quality. J Chromatogr A 1054: 17-31.

Baccouri O, Bendini A, Cerretani L, et al. 2008. Comparative study on volatile compounds from Tunisian and Sicilian monovarietal virgin olive oils. Food Chem 111: 322-328.

Bajoub A, Sánchez-Ortiz A, Ouazzani N, Fernández-Gutiérrez A, Beltrán G, Carrasco-Pancorbo A. 2015. First comprehensive characterization of volatile profile of north Moroccan olive oils: a geographic discriminant approach. Food Res Int 76: 410-417.

Barbieri S, Bendini A, Valli E, Toschi TG. 2015. Do consumers recognize the positive sensorial attributes of extra virgin olive oils related with their composition? A case study on conventional and organic products. J Food Compos Anal 44: 186-195.

Beltran G, Ruano MT, Jimenez A, Uceda M, Aguilera MP. 2007. Evaluation of virgin olive oil bitterness by total phenol content analysis. Eur J Lipid Sci Technol 109: 193-197.

Benito M, Lasa JM, Gracia P, et al. 2013. Olive oil quality and ripening in super-high-density Arbequina orchard. J Sci Food Agric 93: 2207-2220.

Botia J, Ortuno A, Benavente-Garcia O, et al. 2001. Modulation of the biosynthesis of some phenolic compounds in Olea europaea L. fruits: their influence on olive oil quality. J Agric Food Chem 49: $355-358$.

Brkić Bubola K, Koprivnjak O, Sladonja B, Lukić I. 2012. Volatile compounds and sensory profiles of monovarietal virgin olive oil from Buža, Črna and Rosinjola cultivars in Istria (Croatia). Food Technol Biotech 50: 192-198.
Buttery RG, Light DM, Nam Y, Merrill GB, Roitman JN. 2000. Volatile components of green walnut husks. J Agric Food Chem 48: 2858-2861.

Campeol E, Flamini G, Chericoni S, Catalano S, Cremonini R. 2001. Volatile compounds from three cultivars of Olea europaea from Italy. J Agric Food Chem 49: 5409-5411.

Cavalli J-F, Fernandez X, Lizzani-Cuvelier L, Loiseau A-M. 2004. Characterization of volatile compounds of French and Spanish virgin olive oils by HS-SPME: identification of quality-freshness markers. Food Chem 88: 151-157.

Cerretani L, Salvador MD, Bendini A, Fregapane G. 2008. Relationship between sensory evaluation performed by Italian and Spanish official panels and volatile and phenolic profiles of virgin olive oils. Chemosens Percept 1: 258-267.

Commission Regulation (EEC). 2003. Regulation EEC/1989/03, Characteristics of olive and olive-pomace oils and on their analytical methods. Off J Eur Commun L295: 57-77.

Ferreira V, Aznar M, Lopez R, Cacho J. 2001. Quantitative gas chromatography-olfactometry carried out at different dilutions of an extract. Key differences in the odor profiles of four high-quality Spanish aged red wines. J Agric Food Chem 49: 4818-4824.

Folin O, Ciocalteu V. 1927. On tyrosine and tryptophane determinations in proteins. $J$ Biol Chem 73: 627-650.

García-González DL, Aparicio R. 2010. Coupling MOS sensors and gas chromatography to interpret the sensor responses to complex food aroma: application to virgin olive oil. Food Chem 120: $572-579$.

García-González DL, Tena N, Aparicio R. 2007. Characterization of olive paste volatiles to predict the sensory quality of virgin olive oil. Eur J Lipid Sci Technol 109: 663-672.

García-González DL, Aparicio-Ruiz R, Morales MT. 2014. Chemical characterization of organic and non-organic virgin olive oils. $O C L$ 21: D506.

Garcia B, Magalhães J, Fregapane G, Salvador MD, Paiva-Martins F. 2012. Potential of selected Portuguese cultivars for the production of high quality monovarietal virgin olive oil. Eur J Lipid Sci Technol 114: 1070-1082.

Godini A, Vivaldi G, Camposeo S. 2011. Sidebar: olive cultivars field-tested in super-high-density system in southern Italy. Calif Agr 65: 39-40.

Gutiérrez F, Arnaud T, Albi MA. 1999. Influence of ecological cultivation on virgin olive oil quality. J Am Oil Chem Soc 76: 617-621.

International Olive Oil Council (IOOC). 2015a. Available from http:// www.internationaloliveoil.org/documents/index/335-pdf/298-var ios/?lang=fr_FR\&page=3 (last consult: 2016/14/07).

International Olive Oil Council (IOOC). 2015b. COI/T.15/ $\mathrm{NC} \mathrm{n}^{\circ} 3 /$ Rév.8, Norme commerciale applicable aux huiles d'olive et aux huiles de grignons d'olive, pp. 1-20.

International Olive Oil Council (IOOC). 2015c. COI/T.20/Doc. $\mathrm{n}^{\circ} 15 /$ Rév.8, Analyse sensorielle de l'huile d'olive: méthode d'évaluation organoleptique de l'huile d'olive vierge, pp. 1-19.

Kalua CM, Allen MS, Bedgood Jr DR, Bishop AG, Prenzler PD, Robards K. 2007. Olive oil volatile compounds, flavour development and quality: a critical review. Food Chem 100: 273-286.

Kandylis P, Vekiari A, Kanellaki M, Grati Kamoun N, Msallem M, Kourkoutas Y. 2011. Comparative study of extra virgin olive oil flavor profile of Koroneiki variety (Olea europaea var. Microcarpa alba) cultivated in Greece and Tunisia during one period of harvesting. LWT-Food Sci Technol 44: 1333-1341.

Kosma I, Badeka A, Vatavali K, Kontakos S, Kontominas M. 2015. Differentiation of Greek extra virgin olive oils according to cultivar based on volatile compound analysis and fatty acid composition. Eur J Lipid Sci Technol 118: 849-861 
Luaces P, Sanz C, Pérez AG. 2007. Thermal stability of lipoxygenase and hydroperoxide lyase from olive fruit and repercussion on olive oil aroma biosynthesis. J Agric Food Chem 55: 6309-6313.

Mansouri F, Ben Moumen A, Richard G, et al. 2016. Characterization of monovarietal virgin olive oils from introduced cultivars in eastern Morocco. Riv Ital Sostanze Gr 93: 21-30.

Ministère de l'Agriculture et de la Pêche Maritime (MAPM). 2014. Available from http://www.agriculture.gov.ma/pages/acces-fil lieres/filiere-oleicole (last consult: 2016/14/07).

Morales M, Luna G, Aparicio R. 2005. Comparative study of virgin olive oil sensory defects. Food Chem 91: 293-301.

Ollivier D, Boubault E, Pinatel C, Souillol S, Guérère M, Artaud J. 2004. Analyse de la fraction phénolique des huiles d'olive vierges. J Ann Falsif Expert Chim Toxicol 965: 169-196.

Reboredo-Rodríguez P, González-Barreiro C, Cancho-Grande B, Simal-Gándara J. 2013a. Aroma biogenesis and distribution between olive pulps and seeds with identification of aroma trends among cultivars. Food Chem 141: 637-643.

Reboredo-Rodríguez P, Gonzalez-Barreiro C, Cancho-Grande B, Simal-Gańndara J. 2013b. Concentrations of aroma compounds and odor activity values of odorant series in different olive cultivars and their oils. J Agric Food Chem 61: 5252-5259.

Reboredo-Rodríguez P, González-Barreiro C, Cancho-Grande B, Simal-Gándara J. 2014. Quality of extra virgin olive oils produced in an emerging olive growing area in north-western Spain. Food Chem 164: 418-426.

Ridolfi M, Terenziani S, Patumi M, Fontanazza G. 2002. Characterization of the lipoxygenases in some olive cultivars and determination of their role in volatile compounds formation. J Agric Food Chem 50: 835-839.

Russo G, Vivaldi GA, De Gennaro B, Camposeo S. 2014. Environmental sustainability of different soil management techniques in a high-density olive orchard. J Clean Prod 107: 498-508.

Ruther J. 2000. Retention index database for identification of general green leaf volatiles in plants by coupled capillary gas chromatography-mass spectrometry. $J$ Chromatogr A 890: 313-319.

Servili M. 2014. The phenolic compounds: a commercial argument in the economic war to come on the quality of olive oil? OCL 21: D509.

Tanouti K, Serghini Caid H, Sindic M, Wathelet J-P, Bouseta A, Elamrani A. 2012. Volatile compounds, profiles of virgin olive oils produced in the eastern Morocco: oxidative stability and sensory defects. J Food Res 1: 194-206.

Temime SB, Campeol E, Cioni PL, Daoud D, Zarrouk M. 2006. Volatile compounds from Chétoui olive oil and variations induced by growing area. Food Chem 99: 315-325.

Uceda M, Hermoso M. La calidad del aceite de oliva. In: Barranco D, Fernàndez-Escobar R, Rallo L, eds. El cultivo del olivo. Junta de Andalucia Ediciones Mundi-Prensa, Spain, 1998, pp. 547-572.

Umano K, Hagi Y, Shibamoto T. 2002. Volatile chemicals identified in extracts from newly hybrid citrus, dekopon (Shiranuhi mandarin Suppl. J.). J Agric Food Chem 50: 5355-5359.

Vekiari S, Papadopoulou P, Kiritsakis A. 2007. Effects of processing methods and commercial storage conditions on the extra virgin olive oil quality indexes. Grasas Aceites 58: 237-242.

Vichi S, Pizzale L, Conte LS, Buxaderas S, López-Tamames E. 2003. Solid-phase microextraction in the analysis of virgin olive oil volatile fraction: characterization of virgin olive oils from two distinct geographical areas of northern Italy. J Agric Food Chem 51: 6572-6577.

Wong JM, Bernhard RA. 1988. Effect of nitrogen source on pyrazine formation. J Agric Food Chem 36: 123-129.

Zhu H, Li X, Shoemaker CF, Wang SC. 2013. Ultrahigh performance liquid chromatography analysis of volatile carbonyl compounds in virgin olive oils. J Agric Food Chem 61: 12253-12259.

Zhu H, Tang S, Shoemaker CF, Wang SC. 2015. Characterization of volatile compounds of virgin olive oil originating from the USA. J Am Oil Chem Soc 92: 77-85.

Cite this article as: Mansouri F, Ben Moumen A, Richard G, Fauconnier M-L, Sindic M, Serghini Caid H, Elamrani A. 2017. Flavor profiles of monovarietal virgin olive oils produced in the Oriental region of Morocco. OCL 24(5): A501. 